\title{
Uso da informação empresarial no processo de decisão estratégica em empresas de base tecnológica - EBTS: o caso do Centro Empresarial para Laboração de Tecnologias Avançadas -
}

Mauro Sérgio Boppré Goulart

\begin{abstract}
Mestrando da Universidade do Estado de Santa
\end{abstract} Catarina mauro@udesc.br

Pesquisa exploratória desenvolvida na forma de um estudo de caso com o objetivo de investigar o uso da informação empresarial no processo de decisão estratégica nas EBTs do CELTA. A análise dos dados revelou que há, por parte dos gestores das EBTs selecionadas, $O$ reconhecimento da necessidade $e$ relevância das informações estratégicas no processo decisório de gestão. Na prática, não há evidências consistentes do uso efetivo da informação estruturada no processo de decisão estratégica.

Palavras-chave: Informação empresarial; Decisão estratégica; Gestão da informação; Empresa de base tecnológica.

Use of business information in the strategic decision process in technologic basis companies - TBCS: the case of the Bbusiness Center forHandling of Advanced Technologies - CELTA

With the objective of investigating the use of business information in the strategic decision process in TBCs of CELTA this exploratory research was developed as a case study. Data analyses revealed that the TBCs managers know that the strategic information is important and relevant in the managing process of decision taking. However, there is no evidence of the use of the structured information in the process of strategic decision. 
Key-words: Business information; Strategic decision; Information management; Technologic basis company.

Recebido em 01.06.2006 Aceito em 25.10.2006

\section{Introdução}

A sociedade da informação tem criado novos mercados e oportunidades inéditas. Neste ambiente renovado, os empreendedores, impulsionados pela vontade de enfrentar o desafio de abrir seu próprio negócio, muitas vezes não percebem a necessidade de adquirir conhecimentos para desenvolver a capacidade gerencial compatível com tal desafio.

O sucesso de um empreendimento está intrinsecamente relacionado com a capacidade de decidir corretamente. Tomar decisões acertadas é um processo que exige o levantamento de informações, a análise da situação problema, a avaliação das alternativas e a escolha da solução mais adequada. O empreendedor completo é aquele capaz de tomar decisões estratégicas corretas, no momento certo.

Ao investigar o uso da informação empresarial no processo de decisão estratégica, a presente pesquisa buscou contribuir para a melhoria da qualidade das decisões nas empresas de base tecnológica - EBTs -, do CELTA, com a possibilidade de causar um impacto positivo no futuro desenvolvimento da capacidade gerencial dos empreendedores e da capacidade competitiva das empresas. De fato, a real competitividade somente poderá ser obtida por meio de decisões estratégicas competentes, geradoras de inovação.

A pesquisa também tem o potencial de contribuir para a ocupação de um novo espaço de atuação para o profissional bibliotecário, com habilitação em gestão da informação. Novas especializações e profissões estão surgindo a taxas exponenciais, no rastro das inovações tecnológicas e evolução do conhecimento. As próprias organizações, dentro de um processo de reinvenção e ajustamento à realidade em rápida e constante mutação, estão criando novos cargos e carreiras.

A partir dos resultados desta pesquisa, as universidades têm a possibilidade de se alinhar a tais mudanças, oferecendo profissionais qualificados para assumir essas novas funções e minimizando a escassez atual de talentos existente no mercado de trabalho. Poderão desenvolver, ainda, novos projetos de pesquisa e extensão, em parceria com instituições públicas e privadas, com vistas a inovar na formação de profissionais capacitados para especializações e trabalhos inéditos.

\subsection{Formulação do problema}

Localizado no Parque Tecnológico Alfa, em Florianópolis, Santa Catarina, o Centro Empresarial para Laboração de Tecnologias Avançadas 
- CELTA - é um dos centros da Fundação Centro Regional de Tecnologia em Informática - CERTI - e foi criado dentro de uma visão moderna com o objetivo de contribuir para o desenvolvimento sistemático da força empreendedora do país.

Formado por 38 Empresas de Base Tecnológica, o CELTA tem como missão prestar serviços às EBTs, estimulando e apoiando sua criação, desenvolvimento, bem como sua consolidação e interação com o meio empresarial e científico. As EBTs desenvolvem produtos, processos ou serviços inovadores, que resultam de pesquisa científica, para os quais a tecnologia representa alto valor agregado. Normalmente, constituem empreendimentos nas áreas de informática, biotecnologia, química fina, mecânica de precisão e novos materiais. Estão abrigadas em incubadoras de empresas que passam por um processo de seleção e recebem apoio técnico, gerencial e financeiro da rede de instituições formada especialmente para criar e acelerar o desenvolvimento de pequenos negócios.

Um grande desafio para o desenvolvimento e consolidação das EBTs é aprimorar continuamente a habilidade decisória dos empreendedores, assegurando, desta forma, a capacidade de inovação das empresas por meio de novos projetos e programas estrategicamente relevantes. De fato, a inovação, nos tempos atuais, torna-se cada vez mais estratégica para a competição nos negócios. Inovar é diferencial decisivo e determinante do sucesso das empresas.

Neste contexto, conhecimento e informação representam fatores críticos para a inovação em qualquer tipo de empreendimento. Assim, supõe-se que otimizar a qualidade das decisões nas EBTs significa promover a prática da inteligência competitiva por meio do gerenciamento eficiente e eficaz dos fluxos de informações empresariais, atendendo diretamente às necessidades dos empreendedores no processo de decisão estratégica.

Sendo assim, pretende-se, com esta pesquisa, responder aos seguintes questionamentos: as informações empresariais são utilizadas de forma sistemática no processo de decisão estratégica das Empresas de Base Tecnológica do CELTA? O processo de decisão estratégica das EBTs do CELTA utiliza ferramentas estruturadas para a gestão da informação?

\subsection{Objetivos e suposições}

O objetivo geral deste trabalho é analisar o uso da informação empresarial no processo de decisão estratégica nas EBTs, do CELTA. Os objetivos específicos são: a) verificar se as informações empresariais estratégicas estão sendo monitoradas, de forma sistemática, pelas EBTs; b) verificar a existência e o funcionamento de sistemas estruturados para a gestão da informação nas EBTs; e c) analisar o processo de decisão estratégica das EBTs.

As suposições que orientaram a presente pesquisa são as seguintes: a) as informações empresariais não são utilizadas de forma sistemática no 
processo de decisão estratégica das Empresas de Base Tecnológica, do CELTA e b) o processo de decisão estratégica das Empresas de Base Tecnológica tende a ser informal, não utilizando ferramentas estruturadas para a gestão da informação.

\section{Referencial teórico}

A inovação é, nos tempos atuais, fator estratégico central em todas as áreas de atividade e representa um dos mais críticos desafios à gestão empresarial, condicionando a sobrevivência e o desenvolvimento das organizações. Inova-se para explorar as oportunidades que as mudanças geram e evitar as ameaças que podem provocar.

Inovação estrategicamente útil requer uma análise sistemática $e$ contínua do ambiente organizacional externo. A administração precisa assegurar o monitoramento das mudanças no campo de atuação da organização e em áreas correlatas, evidenciando oportunidades subjacentes. Esta análise, normalmente, faz parte de um processo formal de planejamento estratégico nas organizações empresariais. Da análise do ambiente externo resulta a percepção das oportunidades e ameaças ao negócio central (core business) da organização, que determina sua vantagem competitiva.

Como destaca Drucker (1999), o atual contexto ambiental em que as organizações estão inseridas, em sua maioria, é turbulento e, portanto, as forças que exercem maior influência sobre seus negócios vêm de fora delas, e não de dentro. Com isso, a administração não precisa de mais informações sobre o que está acontecendo internamente à organização, mas principalmente de informações sobre o que acontece em seu ambiente externo.

A análise do ambiente externo das organizações se constitui num grande desafio à administração. Marcado por constantes e rápidas mudanças, tal ambiente tem se caracterizado pela complexidade e incerteza latentes, que dificultam seu conhecimento e compreensão.

Para compreender o ambiente externo e seus impactos sobre as organizações torna-se necessário analisá-lo de acordo com seu conteúdo, composto, segundo Stoner e Freeman (1995), por elementos de ação direta e indireta. Os primeiros elementos influenciam diretamente as atividades de uma organização, incluindo fornecedores, governos, grupos de interesses especiais, a mídia, sindicatos de trabalhadores, instituições financeiras e competidores. Já os elementos de ação indireta afetam de forma apenas difusa o contexto em que ocorrem as atividades de uma organização, e envolvem variáveis sociais, econômicas, políticas, tecnológicas, legais, demográficas e ecológicas.

A percepção inteligente do ambiente externo pela administração ocorre, assim, por meio de um conjunto de informações selecionadas e estruturadas, levando à necessidade de uma sondagem permanente das condições ambientais extremamente variáveis. Está ligada à inteligência competitiva, a qual consiste em um processo sistemático de coleta, 
tratamento, análise e disseminação das informações sobre o ambiente externo, com vistas a subsidiar o processo decisório e atingir as metas estratégicas da organização.

No entender de Robins (2001), a sondagem do ambiente organizacional externo envolve a triagem de grandes quantidades de informação empresarial (business information), com o objetivo de detectar tendências emergentes, monitorar ações dos agentes externos e criar cenários estratégicos que apontem tendências futuras sobre os negócios.

A informação empresarial é utilizada pela administração no processo decisório estratégico com o fim de minimizar as incertezas ambientais e identificar novas oportunidades de negócio. Em geral, este tipo de informação tem relação direta com os elementos de ação da análise do ambiente organizacional externo, compreendendo informações mercadológicas, informações jurídicas, informações sobre produtos e serviços, informações governamentais, informações contábeis e financeiras, informações estatísticas, informações tecnológicas, dentre outras.

Segundo Rezende e Abreu (2003), a informação e seus respectivos sistemas desempenham funções fundamentais nas organizações. A informação é um recurso estratégico que tem um valor altamente significativo. Pelo menos são necessários três passos para valorização da informação: conhecer, selecionar e usar a informação. No mesmo sentido, Davenport (1998) argumenta que a valorização da informação se dá pelo seu gerenciamento que envolve a determinação das exigências de informação, sua obtenção, distribuição e utilização.

Cendón (2003) afirma que no Brasil a consciência da necessidade de organização e controle das informações empresariais é recente quando comparada a outros países, e os principais fatores que contribuem para esta situação de atraso são: a) a falta de conhecimento sobre os produtores das fontes de informação empresarial e das fontes em si (qualidade, forma de acesso, organização e volume produzido); b) a falta de conhecimento sobre produtos e serviços de informação que possam suprir a demanda pelas informações empresariais; e c) falta de conhecimento das necessidades dos usuários sobre a informação empresarial.

Cabe destacar que tal situação de atraso tende a afetar negativamente 0 processo de decisão estratégica nas organizações empresariais, especialmente naquelas que não possuem sistemas estruturados para fornecer regularmente informações necessárias à administração, inibindo o desenvolvimento da inteligência competitiva. Como lembra Robins (2001), a qualidade de toda decisão depende fundamentalmente da informação à disposição dos gestores.

Ressalta-se, portanto, que a capacidade para tomar decisões estratégicas rápidas e eficazes depende, cada vez mais, de sistemas estruturados capazes de gerenciar as informações dentro das organizações, promovendo fluxos eficientes. Porém, tal capacidade 
depende, sobretudo, de uma cultura empresarial voltada para a busca de informações estratégicas de forma pró-ativa e crítica, adicionando inteligência à informação empresarial. Isto significa que a agregação de valor às decisões não depende apenas do investimento em novas tecnologias da informação e das habilidades para sua utilização.

Os sistemas de informação possibilitam aprimorar o processo de decisão estratégica, aumentando a qualidade das decisões, por colocarem à disposição da administração informações necessárias, em tempo, local e formato adequados, e por auxiliarem na ampliação de sua percepção acerca do ambiente externo. No entanto, é importante lembrar que a inteligência humana tem prioridade sobre o processo lógico de tomada de decisões, pois dela depende o uso criativo das ferramentas que a própria tecnologia disponibiliza, em ritmo cada vez mais acelerado. Portanto, pode-se concluir que o uso da tecnologia da informação é potencializado pela capacidade gerencial.

Neste sentido, verifica-se que as EBTs são, normalmente, caracterizadas pela existência de uma forte cultura organizacional empreendedora no sentido da inovação tecnológica. Porém, esta mesma cultura não é suficiente à formação de empreendedores com capacidade gerencial necessária para transformar a inovação em instrumento-chave de competição e sobrevivência, tomando decisões estratégicas coerentes e eficazes.

Estudos recentes confirmam este fato. De acordo com Barros (2001), pequenas empresas de prestação de serviços para a Internet não utilizam abordagens formais para o apoio ao processo de tomada de decisão estratégica. Elas tendem a utilizar uma abordagem informal e oportunista, resultado da interação dinâmica de três elementos centrais: incrementalismo; informalidade e networking. Barros (2001) define o incrementalismo como um processo de decisão evolutivo baseado na tentativa e erro; a informalidade como um conjunto de atividades que não utiliza modelos ou ferramentas estruturadas e não possui uma agenda definida, e networking como atividades que compreendem a criação e o desenvolvimento de redes sociais de relacionamento com todos os parceiros de negócio. A pesquisa desse autor revela, assim, a possibilidade de existência de, pelo menos, duas necessidades relacionadas ao desenvolvimento e consolidação de EBTs: a) desenvolvimento da capacidade gerencial dos empreendedores para tomada de decisão estratégica, e b) estruturação de sistemas de informação gerenciais capazes de gerar informação estratégica para o processo decisório, estimulando o desenvolvimento da inteligência competitiva nas organizações.

\section{Metodologia}

A abordagem metodológica utilizada nesta investigação fundamentase na pesquisa qualitativa com enfoque exploratório. Este tipo de pesquisa justifica-se, sobretudo, por ser uma metodologia adequada para 
compreender os aspectos subjetivos da realidade de um conjunto de organizações.

O universo de pesquisa compreende um conjunto de organizações, que neste caso corresponde a uma população de 38 EBTs, localizadas no CELTA. Dessa população foi selecionada uma amostra intencional de 12 EBTs, contendo as seguintes características gerais: o início de suas atividades ocorreu entre 1992 e 2004; os produtos e serviços desenvolvidos são, na sua maioria, softwares e sistemas de automação; o grau de instrução dos empreendedores é superior completo nas áreas de engenharia e computação; possuem em média 17 funcionários e 17 computadores; todas as empresas possuem acesso à internet e à intranet do CELTA.

O princípio da intencionalidade da amostra é adequado ao contexto da pesquisa social com ênfase nos aspectos qualitativos, porque, segundo Thiollent (1986), as unidades investigadas não são consideradas equivalentes, ou de igual relevância.

Este princípio é sistematicamente aplicado no caso em que as unidades investigadas são escolhidas em função de sua representatividade expressiva. A amostra escolhida nesta pesquisa é fundamentada na representatividade expressiva das EBTs selecionadas, conforme critérios de avaliação qualitativos determinados pela gerência do CELTA. Isto significa que a importância das EBTs intencionalmente escolhidas é mais significativa do que seu peso numérico, que corresponde a $32 \%$ da população. Os dados coletados deste grupo de empresas foram considerados mais relevantes ao estudo, embora não possam ser generalizados ao nível do conjunto da população.

As empresas objeto desta pesquisa estão classificadas de acordo com quatro fases de desenvolvimento do empreendimento:

$\checkmark$ Implementação - corresponde ao tempo necessário para a implantação do empreendimento no CELTA. Entre as atividades desenvolvidas nesta fase, estão: legalização do empreendimento; infra-estrutura básica; e operacionalização.

$\checkmark$ Crescimento - compreende o tempo necessário para o empreendimento se consolidar técnica e financeiramente. Nesta fase, o empreendimento deverá alcançar: atendimento às normas técnicas exigidas; instalações laboratoriais; contratação e treinamento de pessoal; registro e aperfeiçoamento dos produtos; identificação de clientes; definição da estratégia de comercialização; capitalização do empreendimento; reavaliação da viabilidade do empreendimento; melhoria das instalações físicas; apoio administrativo.

$\checkmark$ Consolidação - corresponde ao momento em que o empreendedor deve se ater ao fortalecimento econômico da empresa, visando à sua transferência para instalações próprias e definitivas. Deve observar o que segue: produtos em desenvolvimento; treinamento de pessoal; aperfeiçoamento dos produtos; inovação do processo produtivo; aquisição de novos 
clientes; revisão da estratégica de comercialização; capitalização do empreendimento; apoio administrativo; projeto de instalações próprias.

$\checkmark$ Liberação - é relativa ao momento em que a empresa deve estar apta para a transferência definitiva para suas instalações próprias. Nesta fase, o empreendedor deve concentrar-se nas atividades eventualmente não completadas nas fases anteriores e transferir sua empresa para as novas instalações.

Estas fases foram estabelecidas segundo critérios determinados pelo CELTA, sendo selecionadas para esta pesquisa três empresas para cada fase de desenvolvimento.

\subsection{Procedimentos metodológicos}

O procedimento metodológico utilizado é o estudo de caso. De acordo com Gil (1999, p. 73),

o estudo de caso é caracterizado pelo estudo profundo e exaustivo de um ou de poucos objetos, de maneira a permitir conhecimentos amplos e detalhados do mesmo, tarefa praticamente impossível mediante os outros tipos de delineamentos considerados.

$O$ estudo de caso permite conhecer detalhadamente determinado objeto, que pode ser mais de um, em se tratando de um estudo multicaso. Ainda assim, é um estudo aprofundado com revisão bibliográfica, entrevistas e conhecimento da realidade do objeto estudado.

Este estudo compreendeu as seguintes fases: a) revisão da literatura relevante nos campos relacionados às questões de pesquisa; b) desenvolvimento de fundamentação teórica baseada na revisão da literatura pertinente; c) coleta de dados por meio de questionários estruturados, observações e entrevistas semi-estruturadas; d) análise descritiva dos resultados com base em material coletado na pesquisa de campo; e) elaboração das conclusões e recomendações sobre o uso da informação empresarial no processo de decisão estratégica nas EBTs, do CELTA.

O plano de coleta de dados envolveu quatro etapas. Em primeiro lugar, foi elaborado um questionário, com a realização de um pré-teste e revisão do instrumento de pesquisa. De fato, a utilização do questionário proporciona alguns benefícios à pesquisa, como estimular os empreendedores a descreverem exemplos práticos de sua realidade, facilitar o debate em torno das questões propostas e permitir comparações entre as empresas participantes do estudo. A seguir, foram aplicados doze questionários, os quais foram respondidos pelos gestores responsáveis pelas EBTs selecionadas. O questionário foi aplicado como um complemento dos demais instrumentos de coleta de dados, não sendo tomado de forma isolada para justificar as conclusões e recomendações da pesquisa. Em terceiro lugar, foram realizadas doze entrevistas semi- 
estruturadas com os gestores responsáveis pelas EBTs escolhidas, com o intuito de verificar o uso efetivo da informação empresarial estruturada no processo de decisão estratégica. A quarta e última etapa envolveu uma revisão final dos instrumentos de pesquisa aplicados, com a finalidade de evitar possíveis erros e vieses ocorridos na aplicação dos questionários, bem como a realização de observações e entrevistas semi-estruturadas.

\subsection{Categorias analíticas}

As principais categorias de análise utilizadas nesta pesquisa são:

- Informação empresarial - é informação estruturada sobre 0 ambiente organizacional utilizada pela administração no processo

- decisório estratégico com o fim de minimizar as incertezas ambientais e identificar novas oportunidades de negócio;

- gestão da informação - envolve a implantação, utilização e manutenção de sistemas de informações gerenciais estruturados que possuem em suas bases de dados informações que, uma vez agrupadas, criam dispositivos de informação empresarial estruturada, como relatórios, telas, formulários, entre outros dispositivos que aglutinam informações.

- decisão estratégica - corresponde a um processo de análise sistemática de informações empresariais realizada pela alta administração, envolvendo a escolha de alternativas alinhadas ao negócio da organização, que tem como objetivo atingir um posicionamento competitivo capaz de gerar resultados que superem significativamente os padrões de desempenho conhecidos.

\section{Resultados e discussão}

O uso da informação empresarial nos processos de decisão estratégica depende do monitoramento sistemático de tais informações, realizado pela sondagem permanente do ambiente organizacional externo. Das empresas selecionadas para este estudo, oito não realizam o monitoramento sistemático das informações estratégicas.

A preocupação com o monitoramento das informações empresariais parece se concentrar nas empresas localizadas na fase de liberação. Estas empresas utilizam principalmente a Internet para monitorar as informações de que necessitam, promovendo uma diversificação das fontes de pesquisa de informações. Além disso, tal monitoramento recai prioritariamente sobre informações de mercado e clientes. A fala de um gestor entrevistado evidencia isso: "[...] a empresa tem que ter dados 
'trabalhados' para avaliar os clientes e o mercado e assim buscar a visão do negócio através de informações futuras".

A análise que emerge das entrevistas realizadas com os gestores mostra que sete empresas não promovem esforço algum para a classificação, formatação e estruturação das informações. Estas empresas estão localizadas principalmente nas fases de implementação e crescimento. Com isso, verifica-se a falta de um quadro de informações gerenciais, em termos de conteúdo e formato, que atendam às necessidades informacionais dos gestores.

Nas fases de implantação, crescimento e consolidação as empresas não utilizam sistemas de informações estruturados para apoio à tomada de decisões. Isso significa que nessas empresas não são produzidos relatórios padronizados e consultas para os gerentes, pois os fluxos de informações não estão estruturados - são livres e desordenados. O que prevalece em tais empresas é o uso intensivo dos sistemas colaborativos para automação de escritórios que apóiam os grupos e equipes de trabalho. Além disso, vale ressaltar que nessas empresas não existem pessoas ou setores responsáveis pela gestão da informação e o processo decisório tende a ser informal e descentralizado. Isso pode ser demonstrado pela afirmação de um gestor entrevistado:

[...] para a empresa a informação é o ar que se respira [...] um ativo muito importante para desenvolver novos produtos e serviços [...] A empresa tem o comando descentralizado e informal e todos têm livre acesso à informação. Não há necessidade de uma pessoa/setor responsável pela gestão da informação [...] preferimos que todos busquem a informação. A empresa armazena as informações em reservatórios locais ou em pastas de documentos.

Mesmo nas empresas que se encontram na fase de liberação, constata-se que a preocupação com sistemas de informações gerenciais é recente, o que se deve a dois fatores preponderantes: a falta de cultura organizacional favorável e o alto custo dos sistemas de informação. As falas de três gestores entrevistados confirmam isso:

É recente o olhar da empresa sobre os benefícios de se ter as informações organizadas [...] quando começamos não tínhamos a necessidade de gerar relatórios. Nos primeiros planos de negócios os resultados eram estimados, mas agora com o passar dos anos revendo os planos existem dados reais, e estamos correndo atrás para saber onde eles estão [...] há preocupação de mudar a cultura da empresa em todos os seus setores para aprender a formatar melhor seus relatórios [...] a dedicação atual dos executivos da empresa é para a área financeira.

Não há como tomar uma decisão sem informação [...] você paga um alto custo por utilizar uma informação errada [...] a 
informação custa muito caro e os sistemas para administrá-la também [...], porém, sabemos dos benefícios de utilizar sistemas estruturados para gestão da informação [...] estamos adquirindo um novo programa para isso, porém esse novo sistema só atenderá $80 \%$ das necessidades de informação da empresa.

A empresa possui cultura de TI e utiliza sistemas de gestão da informação [...] a tomada de decisão está centrada na alta administração [...], porém, pretendemos estender aos níveis operacionais [...] estamos promovendo a mudança da cultura em toda a empresa.

Nenhuma das empresas pesquisadas relatou, de forma consistente, que adota uma abordagem estruturada com relação ao uso da informação no processo de decisão estratégica. Isso é corroborado pela constatação do fraco monitoramento sistemático das informações estratégicas, da carência de relatórios gerenciais estruturados e da insuficiência de infraestrutura adequada para o tratamento da informação.

No entanto, constata-se o reconhecimento por parte dos gestores da necessidade de utilização de informações geradas por sistemas estruturados para a eficácia do processo de decisão estratégica, conforme afirmam três gestores entrevistados:

Por causa do investidor a empresa tem de seguir normas rígidas quanto ao cumprimento das etapas do planejamento estratégico [...] achamos fundamental possuir um sistema de informação estruturado para apoiar o processo de tomada de decisão na empresa.

Os administradores estão envolvidos mais na área operacional [...] sem tempo para trabalhar o fluxo de informação na empresa [...] e a empresa está sentindo falta de dados para saber como está seu desempenho [...] a empresa está em fase de mudança e sabe da necessidade de possuir um sistema de informação atualizado [...] buscamos adquirir um software que meça todos os processos e tarefas internas.

É fundamental usar a informação para gerar boas idéias e saber da viabilidade dessa idéia no mercado. Toda informação que você recebe através do benchmarking, plano de negócio, planejamento estratégico etc... é que indicará se um produto gerará resultados ou não. A informação deve estar casada ou cruzada para saber se a empresa vai gerar lucro.

Os resultados deste estudo indicam o deficiente monitoramento das informações estratégicas nas empresas pesquisadas, principalmente naquelas situadas nas três fases iniciais de desenvolvimento dos empreendimentos. Dessa forma, constata-se a necessidade de se identificar como os gestores percebem seus ambientes informacionais e a 
diferença entre as informações que desejam daquelas que realmente precisam.

Percebe-se a necessidade de estimular os gestores a elaborarem um quadro ideal de informações gerenciais (internas e externas) em termos de conteúdo em relação aos objetivos da organização. A partir desse quadro, as informações devem ser analisadas quanto à sua relevância e em seguida classificadas de acordo com os seguintes critérios: informações estratégicas essenciais, informações úteis e informações desejáveis, mas não essenciais. É preciso, portanto, definir diretrizes quanto ao processo de gerar informações nestas empresas.

Outro aspecto importante se refere à insuficiência, nas empresas estudadas, de infra-estrutura necessária à gestão da informação. Os sistemas de informação não estão estruturados para apoio ao processo decisório estratégico e não existem pessoas ou setores específicos para gerenciar as informações de forma eficaz. Verifica-se, assim, a necessidade de estrutura, recursos e investimentos para a geração de informações estratégicas essenciais dentro de padrões de qualidade e prazos desejáveis.

Quanto ao uso efetivo das informações estratégicas, a pesquisa demonstrou que não existem evidências consistentes de tal uso, uma vez que há carência de relatórios estruturados emitidos por meio de sistemas de informações gerenciais. Portanto, faz-se mister a elaboração de relatórios estruturados padronizados, que possam suprir as necessidades de informações dos gestores das empresas pesquisadas.

Porém, cabe salientar a necessidade da busca pró-ativa de informações críticas, por parte dos gestores, em contraposição a uma postura passiva. A dinâmica de rápidas mudanças externas e internas faz com que os sistemas de informações gerenciais estejam sempre incompletos e desajustados, exigindo esforços extras dos executivos. Dessa forma, os gestores precisam, ao administrar os sistemas de informações gerenciais, ter consciência de que faz parte de sua responsabilidade buscar informações críticas, fazendo análises e chegando a conclusões próprias. Esta consciência tornará o processo de busca mais estimulante e assegurará às empresas um nível de qualidade das informações cada vez melhor.

\section{Conclusão e recomendações}

A análise dos dados revelou que há, por parte dos gestores das EBTs selecionadas, o reconhecimento da necessidade e relevância das informações estratégicas no processo decisório de gestão. Porém, na prática, não há evidências consistentes sobre o uso efetivo da informação estruturada no processo de decisão estratégica, corroborada pela constatação do fraco monitoramento sistemático das informações estratégicas, da carência de relatórios gerenciais estruturados e da insuficiência de infra-estrutura adequada para o tratamento da informação. A partir desta constatação recomenda-se às empresas e à 
gerência do CELTA a observação de alguns fatores que poderão tornar efetivo o uso da informação estratégica nos processos de tomada de decisão das empresas.

Inicialmente, devem ser incluídos, nos planos de negócios apresentados pelas empresas, aspectos relacionados com a gestão da informação, no sentido de se reconhecer o gerenciamento da informação como recurso fundamental para a performance do desempenho gerencial e de se considerar o uso efetivo dos sistemas de informações gerenciais.

Além disto, devem ser realizados investimentos para a criação de uma infra-estrutura própria à gestão da informação a ser compartilhada pelas empresas, obedecendo-se níveis apropriados de acessibilidade e segurança. Essa infra-estrutura seria composta de tecnologias de informação e comunicação adequadas ao tratamento técnico das informações estratégias para as EBTs e também de profissionais da informação qualificados para realizar uma revisão completa dos sistemas de informações, objetivando à permanente educação e sensibilização dos gestores das empresas quanto à relevância desse assunto.

Finalmente, deve-se procurar estimular a formação de uma cultura organizacional voltada para o uso efetivo da informação no processo decisório de gestão. Tal cultura poderá contribuir para que os gestores das EBTs utilizem informações estruturadas para tomar decisões estratégicas.

\section{Referências}

BARROS, Marco A. Estratégia nas empresas de internet: lições da informalidade. Revista de Administração de Empresas, São Paulo, v. 41, n. 4, p. 32-43, out./dez. 2001.

CENDÓN, Beatriz V. Bases de dados de informação para negócios no Brasil. Ciência da Informação, Brasília, v. 32, n. 2, p. 17-36, maio/ago. 2003.

DAVENPORT, T. H. Ecologia da informação. 4. ed. São Paulo: Futura, 1998.

DRUCKER, P. Sociedade pós-capitalista. São Paulo: Pioneira, 1999.

GIL, A. C. Métodos e técnicas de pesquisa social. 5. ed. São Paulo: Atlas, 1999.

REZENDE, D. A.; ABREU, A. F. de. Tecnologia da informação: aplicada a sistemas de informações empresariais. 3. ed. São Paulo: Atlas, 2003.

ROBBINS, S. P. Administração: mudanças e perspectivas. São Paulo: Saraiva, 2001.

STONER, J. A. F.; FREEMAN, R. E. Administração. 5. ed. Rio de Janeiro: Prentice Hall do Brasil, 1995.

THIOLLENT, M. Metodologia da pesquisa-ação. 3. ed. São Paulo: Cortez, 1986. 